American Journal of Infectious Diseases 6 (1): 1-7, 2010

ISSN 1553-6203

(C) 2010 Science Publications

\title{
Antimicrobial Susceptibility of Bloodstream Isolates of Staphylococcus aureus: Global Results from the Tigecycline Evaluation and Surveillance Trial, 2004-2008
}

\author{
${ }^{1}$ Daniel Amsterdam, ${ }^{2}$ Geoffrey Coombs and ${ }^{3}$ Michael Dowzicky \\ ${ }^{1}$ Erie County Medical Center, Department of Microbiology and Immunology, \\ School of Medicine and Biomedical Sciences, University at Buffalo, \\ 462 Grider Street, Buffalo, NY 14215 USA \\ ${ }^{2}$ Royal Perth Hospital, Department of Microbiology and Infectious Diseases, WA, Australia \\ ${ }^{3}$ Wyeth Pharmaceuticals, Infectious Disease Group, Collegeville, PA, USA
}

\begin{abstract}
Problem statement: The Tigecycline Evaluation and Surveillance Trial (TEST) commenced in 2004 to monitor the activity of tigecycline, a new glycylcycline and numerous comparators against major hospital-and community-associated pathogens. In this report we examine the efficacy of tigecycline and comparators against isolates of Staphylococcus aureus collected from blood. Approach: Almost 4000 blood-derived isolates of Staphylococcus aureus were collected from participating centers globally between 2004-2008. Results: All isolates were susceptible to tigecycline $\left(\mathrm{MIC}_{90} 0.25 \mathrm{mg} \mathrm{L}^{-1}\right.$ ) and linezolid $\left(\mathrm{MIC}_{90} 4 \mathrm{mg} \mathrm{L}^{-1}\right)$; $99.9 \%$ of isolates were susceptible to vancomycin $\left(\mathrm{MIC}_{90} 1 \mathrm{mg} \mathrm{L}^{-1}\right.$ ). Tigecycline and linezolid activity were unaffected by resistance to methicillin, ICU vs non-ICU isolate collection or the age of patients from which the isolates were collected. Although $95.3 \%$ of MSSA were levofloxacin susceptible, only $14.4 \%$ of MRSA isolates were susceptible to levofloxacin in this study. Conclusion: Tigecycline is shown here to be active against $S$. aureus isolates collected from blood and is unaffected by methicillin resistance. However, tigecycline is not as yet approved for the treatment of bacteremic infections.
\end{abstract}

Key words: MRSA, surveillance, bacteremia, resistance, tigecycline

\section{INTRODUCTION}

Antimicrobial resistance among a variety of bacterial pathogens is now well documented and is an increasingly important consideration when evaluating therapeutic choice and healthcare cost (McDonald, 2006; Chastre, 2008; Isturiz, 2008). Increases in antimicrobial resistance have led to increased patient morbidity and mortality as well as increased length of hospital stay and health care costs (Cosgrove, 2006). The escalations in antimicrobial resistance have presented challenges to healthcare providers, making the selection of effective empiric therapy increasingly difficult (Deasy, 2009).

Staphylococcus aureus continues to be a common cause of serious infections, including those involving the bloodstream and antimicrobial therapy of this organism is complicated by the evolution of Methicillin (MRSA) and Multi-Drug (MDR) resistant strains (Lodise and McKinnon, 2005; Rehm et al., 2009). MRSA is an important risk factor for other serious illnesses, including novel H1N1 influenza infection
(Shannon et al., 2009). MRSA can also be a significant contributor to mortality: Klein et al. (2007) estimated that 5500 MRSA-related deaths occurred annually in the US between 1999 and 2005, while the Office for national statistics in the UK has reported a maximum of 1629 MRSA-related deaths, occurring in 2005 (Office for National Statistics, 2009). In Australia and New Zealand where invasive S. aureus infection is associated with substantial mortality, significant rates of MRSA and the suboptimal antimicrobials available for treatment of these strains have been shown to exacerbate the problem (Turnidge et al., 2009).

Tigecycline (Wyeth Pharmaceuticals, Collegeville, PA, USA) is the first clinically available representative of a new class of antimicrobials, the glycylcyclines, which are derived from the tetracycline nucleus. Tigecycline (Fig. 1) is characterized by a broad spectrum of potent antibacterial activity and remains active against many strains expressing tetracycline and multi-drug resistance (Felmingham, 2005; Zhanel et al., 2006).

Corresponding Author: Daniel Amsterdam, Erie County Medical Center, Department of Microbiology and Immunology, School of Medicine and Biomedical Sciences, University at Buffalo, 462 Grider Street, Buffalo, NY 14215 USA Tel: 1-716-898-3000 Fax: 1-716-898-3090 
Am. J. Infect. Dis., 6 (1): 1-7, 2010<smiles>CN(C)c1cc(NC(=O)CNC(C)(C)C)c(O)c2c1C[C@H]1C[C@H]3[C@H](N(C)C)C(O)=C(C(N)=O)C(=O)[C@@]3(O)C(O)=C1C2=O</smiles>

Fig. 1: Structural formula of tigecycline

Antimicrobial susceptibility surveillance is an important strategy in understanding the evolution of antimicrobial resistance and providing information as an aid to optimizing the empirical therapy of bacterial infections (Felmingham, 2002). The Tigecycline Evaluation and Surveillance Trial (TEST), established in 2004, is a global surveillance study designed to compare the in vitro activity of tigecycline with a panel of antimicrobials used in daily practice, against a range of clinically important bacterial species including $S$. aureus. Tigecycline is indicated in the treatment of complicated Skin and Skin Structure Infections (cSSSIs), complicated Intra-Abdominal Infections (cIAIs) and Community-Acquired Bacterial Pneumonia (CABP) caused by penicillin-susceptible $S$. pneumoniae or $\beta$-lactamase negative $H$. influenzae (Wyeth Pharmaceuticals Inc, 2009a; 2009b). This study reports on the comparative in vitro susceptibility of bloodstream isolates of $S$. aureus examined during the sampling period 2004-2008. Tigecycline is not indicated for the treatment of bloodstream infections (Wyeth Pharmaceuticals Inc, 2009a; 2009b).

\section{MATERIALS AND METHODS}

Bacterial isolates: Bloodstream isolates of $S$. aureus were collected consecutively by centers participating in TEST, with only one isolate per patient included in the study. Data on a total of 3927 bloodstream isolates of S. aureus were submitted to the TEST during the period 2004-2008. Of this total, 3629/3927 (92.4\%) provided data enabling division of isolates into those sourced from patients treated on either non-ICU or ICU and $3544 / 3927(90.2 \%)$ could be separated into those patients aged 18-64 years and those $\geq 65$ years of age (Table 1).

Collection, transport and confirmation of isolate identification were organized by Laboratories International for Microbiology Studies, a division of International Health Management Associates (IHMA, Schaumburg, Ill., USA) which also managed a centralized database of isolate information.
Isolates were identified according to the American Society for Microbiology procedure for $S$. aureus (Murray, 2007).

Antimicrobial susceptibility testing: Minimum Inhibitory Concentrations (MICs) of the antimicrobials included in the analysis were determined locally by participating centers using the Clinical Laboratory Standards Institute (CLSI) broth microdilution method (CLSI, 2009a) with either Microscan ${ }^{\circledR}$ panels (Dade Behring, Sacramento, Calif., USA) or Sensititre ${ }^{\circledR}$ plates (TREK Diagnostic Systems, East Grinstead, UK). Isolates of $S$. aureus were tested against the following antimicrobials (concentration ranges tested expressed in $\left.\mathrm{mg} \mathrm{L}^{-1}\right)$ : penicillin (0.06-8); amoxicillin/clavulanic acid (0.03/0.015-8/4); piperacillin/tazobactam (0.25/416/4); ceftriaxone (0.03-64); imipenem (0.12-16, Microscan $₫$ only); meropenem (0.12-16, Sensititre $₫$ only); levofloxacin (0.06-32); linezolid (0.5-8); vancomycin (0.12-32); minocycline (0.25-8) and tigecycline (0.008-16). Imipenem was removed from the TEST and replaced by meropenem in 2006 because of imipenem stability issues. Quality control testing was carried out on each day of testing using $S$. aureus strain ATCC 29213. For all antimicrobials except tigecycline, MICs were interpreted using criteria published by the CLSI (2009b). In the case of tigecycline, isolates of $S$. aureus requiring $\mathrm{MIC}$ of $\leq 0.5 \mathrm{mg} \mathrm{L}^{-1}$ were interpreted as susceptible, as recommended by the US Food and Drug Administration (Wyeth Pharmaceuticals Inc, 2009a; 2009b).

Determination of methicillin resistance: All isolates of S. aureus were tested for the methicillin-resistant phenotype using the cefoxitin disk diffusion method (30 $\mu \mathrm{g}$ disks; Remel, Lenexa, KA, USA) by IHMA's central laboratory (Murray, 2007).

Quality assurance: All isolates were subjected to a Quality Assurance Programme (QAP) designed by IHMA, which incorporated more than 150 individual QA checks to screen for atypical susceptibility patterns or other discrepant results. In the case of $S$. aureus, some of these checks included tigecycline MIC $>0.25 \mathrm{mg} \mathrm{L}^{-1}$, penicillin-susceptible and carbapenem or any beta-lactam-resistance and non-susceptibility to linezolid or vancomycin; some specific checks for MRSA were non-resistance to penicillin, susceptibility to carbapenems and resistance to amoxicillin/clavulanic acid and non-susceptibility to quinupristin/dalfopristin.

Isolates with atypical results were re-evaluated with regard to purity and identification followed by re-testing by the central laboratory using the same antimicrobial panel supplied to the investigator labs. 
Am. J. Infect. Dis., 6 (1): 1-7, 2010

Table 1: Comparative distribution of MRSA amongst blood isolates of Staphylococcus aureus cultured from non-ICU and ICU patients and patients of 18-64 or $\geq 65$ years of age, examined in the TEST programme, 2004-2008

\begin{tabular}{lllllrr}
\hline Year(s) of study & 2004 & 2005 & 2006 & 2007 & 2008 & $2004-2008$ \\
\hline Non-ICU and ICU patient isolates & 495 & 658 & 772 & 1063 & 641 & 3629 \\
S. aureus from non-ICU patients (\%) & $393(79.4)$ & $505(76.7)$ & $603(78.1)$ & $847(79.7)$ & $495(77.2)$ & $2843(78.3)$ \\
MRSA from non-ICU patients (\%) & $171(43.5)$ & $232(45.9)$ & $234(38.8)$ & $285(33.6)$ & $163(32.9)$ & $1085(38.2)$ \\
S. aureus from ICU patients (\%) & $102(20.6)$ & $153(23.3)$ & $169(21.9)$ & $216(20.3)$ & $146(22.8)$ & $786(21.7)$ \\
MRSA from ICU patients (\%) & $54(52.9)$ & $70(45.8)$ & $80(47.3)$ & $99(45.8)$ & $55(37.7)$ & $358(45.5)$ \\
Isolates from patients aged 18-64 and $\geq 65$ years & 478 & 633 & 740 & 1033 & 660 & 3544 \\
S. aureus from patients aged 18-64 years (\%) & $259(54.2)$ & $355(56.1)$ & $391(52.8)$ & $577(55.9)$ & $368(55.8)$ & $1950(55.0)$ \\
MRSA from patients aged 18-64 years (\%) & $112(43.2)$ & $155(43.7)$ & $143(36.6)$ & $209(36.2)$ & $102(27.7)$ & $721(37.0)$ \\
S. aureus from patients aged $\geq 65$ years (\%) & $219(45.8)$ & $278(43.9)$ & $349(47.2)$ & $456(44.1)$ & $292(44.2)$ & $1594(45.0)$ \\
MRSA from patients aged $\geq 65$ years (\%) & $113(51.6)$ & $136(48.9)$ & $162(46.4)$ & $187(41.0)$ & $116(39.7)$ & $714(44.8)$ \\
\hline
\end{tabular}

Isolates generating atypical results on retesting were reviewed by an in-house panel of microbiologists and either accepted and re-inserted into the database or retested a second time. Atypical results generated on three separate occasions were accepted into the TEST database.

\section{RESULTS}

Bloodstream isolates of $S$. aureus submitted to TEST and reported in this study were collected from centers in the following regions during the period 20042008: Africa, the Asia/Pacific Rim, Europe, Latin America, the Middle East and North America (Fig. 2). In view of the relatively small numbers of isolates submitted annually from individual regions (with the exception of methicillin resistance) susceptibility data are reported on combined isolates from all years and regions.

While isolates of $S$. aureus from patients treated on non-ICU outnumber those from ICU almost 4-fold (2843 (78.3\%) Vs $786(21.7 \%)$ ), isolates from patients aged 1864 years and from those of $\geq 65$ years are more evenly distributed (1950 (55.0\%) Vs 1594 (45\%)) (Table 1).

Overall rates of methicillin resistance (MRSA) are somewhat higher in patients treated in ICUs compared with the non-ICU setting $(45.5 \%$ Vs $38.2 \%$, respectively) (Table 1).

Of the combined total of 3927 bloodstream isolates of Staphylococcus aureus submitted to TEST during the period 2004-2008, 2397 (61.0\%) are methicillin susceptible (MSSA) and 1530 are MRSA (Table 2). All isolates of MSSA and MRSA are susceptible to tigecycline $\left(\mathrm{MIC}_{90} 0.25 \mathrm{mg} \mathrm{L}^{-1}\right.$; $\mathrm{MIC}_{100} 0.5 \mathrm{mg} \mathrm{L}^{-1}$ ) and linezolid ( $\mathrm{MIC}_{90} 4 \mathrm{mg} \mathrm{L}{ }^{-1} ; \mathrm{MIC}_{100} 4 \mathrm{mg} \mathrm{L}^{-1}$ ). Predictably, tigecycline retains activity against the small number of isolates not fully susceptible to minocycline. Most (99.9\%) of the isolates of MSSA and of MRSA are susceptible to vancomycin with only three isolates of MSSA and one of MRSA requiring an MIC of $4 \mathrm{mg} \mathrm{L}^{-1}, 2$ fold greater than the susceptibility breakpoint of $2 \mathrm{mg} \mathrm{L}^{-1}$ (but not above the CLSI-defined resistant breakpoint of $16 \mathrm{mg} \mathrm{L}^{-1}$ ) (Table 2).

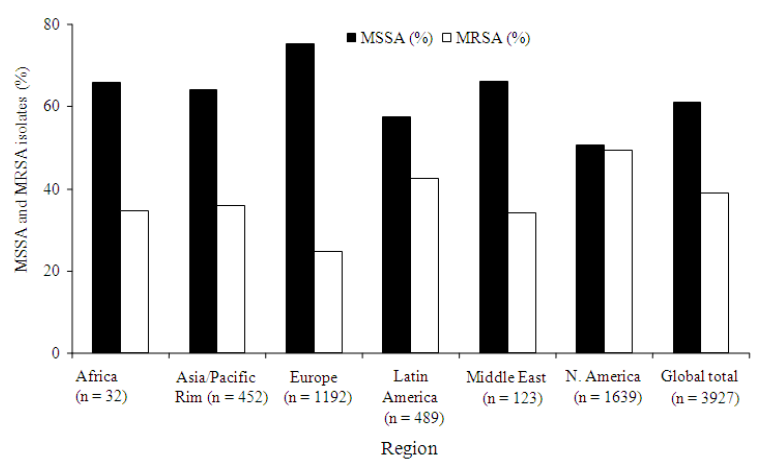

Fig. 2: Geographical distribution of blood isolates of methicillin-susceptible (MSSA) and methicillinresistant Staphylococcus aureus (MRSA) examined in the TEST programme: 2004-2008 combined isolates

While only $17.6 \%$ of isolates of MSSA are susceptible to penicillin, the staphylococcal betalactamase-stable compounds included in the study are generally highly active against these strains (amoxicillin/clavulanic acid, $99.9 \%$ of isolates tested susceptible; piperacillin/tazobactam, $100 \%$ susceptible; ceftriaxone, $98.9 \%$ susceptible; imipenem, $99.9 \%$ of 945 isolates tested susceptible; meropenem, $99.9 \%$ of 1452 susceptible) (Table 2). All isolates of MRSA are considered clinically resistant to these compounds according to CLSI guidelines (CLSI, 2009a: 2009b).

The most obvious difference in susceptibility between MSSA and MRSA is with the fluoroquinolone, levofloxacin. Most (95.3\%) isolates of MSSA are susceptible to this compound, compared with only $14.4 \%$ of MRSA (Table 2). Levofloxacin susceptibility increased significantly among $S$. aureus isolates from blood between $2004(59.2 \%$ S) and 2008 (68.7\% S) $(\mathrm{p}<0.0001$. MRSA susceptibility to levofloxacin increased $(p=0.001)$ while MSSA susceptibility decreased $(p=0.0167)$ during this interval. Data for 2008 are incomplete at this point, however, so the reliability of these trends is uncertain. 
Am. J. Infect. Dis., 6 (1): 1-7, 2010

Table 2: Comparative in vitro activity of tigecycline against 3927 blood isolates of Staphylococcus aureus examined in the TEST programme,

\begin{tabular}{|c|c|c|c|c|c|c|c|c|c|c|}
\hline \multirow[b]{2}{*}{ Antimicrobial } & \multicolumn{5}{|c|}{ MSSA MIC $\left(\mathrm{mg} \mathrm{L}^{-1}\right)$} & \multicolumn{5}{|c|}{ MRSA MIC $\left(\mathrm{mg} \mathrm{L}^{-1}\right)$} \\
\hline & $\mathrm{n}$ & $50 \%$ & $90 \%$ & Range & $\mathrm{S}(\%)$ & $\mathrm{n}$ & $50 \%$ & $90 \%$ & Range & $\mathrm{S}(\%)$ \\
\hline Penicillin & 2397 & 4.00 & $\geq 16.00$ & $\leq 0.06-\geq 16$ & 17.6 & 1530 & $\geq 16.00$ & $\geq 16.00$ & $0.25-\geq 16$ & $0.0^{*}$ \\
\hline Amoxycillin/clavulanic acid & 2397 & 1.00 & 2.00 & $\leq 0.03-\overline{8}$ & 99.9 & 1530 & 8.00 & $\geq 16.00$ & $0.25-\geq 16$ & $0.0^{*}$ \\
\hline Piperacillin/tazobactam & 2397 & 1.00 & 2.00 & $\leq 0.25-8$ & 100.0 & 1530 & $\geq 32.00$ & $\geq 32.00$ & $\leq 0.25-\geq 32$ & $0.0^{*}$ \\
\hline Ceftriaxone & 2397 & 2.00 & 4.00 & $0.25-\geq 128$ & 98.9 & 1530 & 64.00 & $\geq 128.00$ & $\leq 0.03-\geq 128$ & $0.0^{*}$ \\
\hline Imipenem & 945 & $\leq 0.12$ & 0.25 & $\leq 0.12-\overline{8}$ & 99.9 & 717 & 1.00 & $\geq 32.00$ & $\leq 0.12-\geq 32$ & $0.0^{*}$ \\
\hline Meropenem & 1452 & $\leq 0.12$ & 0.25 & $\leq 0.12-8$ & 99.9 & 813 & 4.00 & $\geq 32.00$ & $\leq 0.12-\geq 32$ & $0.0 *$ \\
\hline Levofloxacin & 2397 & 0.12 & 0.50 & $\leq 0.06-\geq 64$ & 95.3 & 1530 & 8.00 & $\geq 64.00$ & $\leq 0.06-\geq 64$ & 14.4 \\
\hline Linezolid & 2397 & 2.00 & 4.00 & $\leq 0.5-4$ & 100.0 & 1530 & 2.00 & 4.00 & $\leq 0.5-4$ & 100.0 \\
\hline Vancomycin & 2397 & 1.00 & 1.00 & $\leq 0.12-4$ & 99.9 & 1530 & 1.00 & 1.00 & $\leq 0.12-4$ & 99.9 \\
\hline Minocycline & 2397 & $\leq 0.25$ & 0.50 & $\leq 0.25-\geq 16$ & 99.4 & 1530 & $\leq 0.25$ & 4.00 & $\leq 0.25-\geq 16$ & 94.4 \\
\hline Tigecycline & 2397 & 0.12 & 0.25 & $0.015-0.5$ & 100.0 & 1530 & 0.12 & 0.25 & $\leq 0.008-0.5$ & 100.0 \\
\hline
\end{tabular}

*: All MRSA defined as resistant to penicillinase-labile penicillins, according to CLSI guidelines (11)

Table 3:Comparative in vitro activity of tigecycline against 3629 blood isolates of Staphylococcus aureus from non-ICU and ICU patients examined in the TEST programme, 2004-2008

\begin{tabular}{|c|c|c|c|c|c|c|c|c|c|c|}
\hline \multirow[b]{2}{*}{ Antimicrobial } & \multicolumn{5}{|c|}{ Non-ICU patient isolates $\mathrm{MIC}\left(\mathrm{mg} \mathrm{L}^{-1}\right)$} & \multicolumn{5}{|c|}{ ICU patient isolates $\mathrm{MIC}\left(\mathrm{mg} \mathrm{L}^{-1}\right)$} \\
\hline & $\mathrm{n}$ & $50 \%$ & $90 \%$ & Range & $\mathrm{S}(\%)$ & $\mathrm{n}$ & $50 \%$ & $90 \%$ & Range & $\mathrm{S}(\%)$ \\
\hline \multicolumn{11}{|l|}{ Methicillin-suceptible isolates } \\
\hline Penicillin & 1758 & 4.00 & $\geq 16.00$ & $\leq 0.06-\geq 16$ & 17.6 & 428 & 8.00 & $\geq 16.00$ & $\leq 0.06-\geq 16$ & 16.8 \\
\hline Amoxycillin/clavulanic acid & 1758 & 1.00 & 2.00 & $\leq 0.03-\overline{8}$ & 99.9 & 428 & 1.00 & 2.00 & $0.06-\overline{8}$ & 99.8 \\
\hline Piperacillin/tazobactam & 1758 & 1.00 & 2.00 & $\leq 0.25-8$ & 100.0 & 428 & 1.00 & 1.00 & $\leq 0.25-8$ & 100.0 \\
\hline Ceftriaxone & 1758 & 2.00 & 4.00 & $0.25-\geq 128$ & 99.1 & 428 & 2.00 & 4.00 & $0.25-\geq 128$ & 97.9 \\
\hline Imipenem & 697 & $\leq 0.12$ & 0.25 & $\leq 0.120-1$ & 100.0 & 179 & $\leq 0.12$ & 0.25 & $\leq 0.12-\overline{8}$ & 99.4 \\
\hline Meropenem & 1061 & $\leq 0.12$ & 0.25 & $\leq 0.12-8$ & 99.8 & 249 & $\leq 0.12$ & 0.25 & $\leq 0.12-4$ & 100.0 \\
\hline Levofloxacin & 1758 & 0.12 & 0.50 & $\leq 0.06-\geq 64$ & 94.9 & 428 & 0.12 & 0.50 & $\leq 0.06-32$ & 96.7 \\
\hline Linezolid & 1758 & 2.00 & 4.00 & $\leq 0.5-4$ & 100.0 & 428 & 2.00 & 2.00 & $\leq 0.5-4$ & 100.0 \\
\hline Vancomycin & 1758 & 1.00 & 1.00 & $\leq 0.12-4$ & 99.9 & 428 & 1.00 & 1.00 & $\leq 0.12-4$ & 99.8 \\
\hline Minocycline & 1758 & $\leq 0.25$ & 0.50 & $\leq 0.25-\geq 16$ & 99.5 & 428 & $\leq 0.25$ & 0.50 & $\leq 0.25-\geq 16$ & 98.8 \\
\hline Tigecycline & 1758 & 0.12 & 0.25 & $0.03-0.5$ & 100.0 & 428 & 0.12 & 0.25 & $0.015-0.5$ & 100.0 \\
\hline \multicolumn{11}{|l|}{ Methicillin-resistant isolates } \\
\hline Levofloxacin & 1085 & 16.00 & $\geq 64.00$ & $\leq 0.06-\geq 64$ & 13.9 & 358 & 8.00 & $\geq 64.00$ & $\leq 0.06-\geq 64$ & 14.8 \\
\hline Linezolid & 1085 & 2.00 & 4.00 & $\leq 0.5-4$ & 100.0 & 358 & 2.00 & 2.00 & $\leq 0.5-4$ & 100.0 \\
\hline Vancomycin & 1085 & 1.00 & 1.00 & $\leq 0.12-4$ & 99.9 & 358 & 1.00 & 1.00 & $\leq 0.12-2$ & 100.0 \\
\hline Minocycline & 1085 & $\leq 0.25$ & 4.00 & $\leq 0.25-\geq 16$ & 94.8 & 358 & $\leq 0.25$ & 4.00 & $\leq 0.25-\geq 16$ & 91.9 \\
\hline Tigecycline & 1085 & 0.12 & 0.25 & $\leq 0.008-0.5$ & 100.0 & 358 & 0.12 & 0.25 & $\leq 0.008-0.5$ & 100.0 \\
\hline
\end{tabular}

Table 4: Comparative in vitro activity of tigecycline against 3544 blood isolates of Staphylococcus aureus from patients aged 18-64 years and $\geq 65$ years examined in the TEST programme, 2004-2008

\begin{tabular}{|c|c|c|c|c|c|c|c|c|c|c|}
\hline \multirow[b]{2}{*}{ Antimicrobial } & \multicolumn{5}{|c|}{ Patients aged 18-64 years MIC $\left(\mathrm{mg} \mathrm{L}^{-1}\right)$} & \multicolumn{5}{|c|}{ Patients aged $\geq 65$ years MIC $\left(\mathrm{mg} \mathrm{L}^{-1}\right)$} \\
\hline & $\mathrm{n}$ & $50 \%$ & $90 \%$ & Range & $\mathrm{S}(\%)$ & $\mathrm{n}$ & $50 \%$ & $90 \%$ & Range & $\mathrm{S}(\%)$ \\
\hline \multicolumn{11}{|c|}{ Methicillin-susceptible isolates } \\
\hline Penicillin & 1229 & 4.00 & $\geq 16.00$ & $\leq 0.06-\geq 16$ & 16.7 & 880 & 4.00 & $\geq 16.00$ & $\leq 0.06-\geq 16$ & 19.9 \\
\hline Amoxycillin/clavulanic acid & 1299 & 1.00 & 2.00 & $0.06-\overline{8}$ & 99.8 & 880 & 0.50 & 1.00 & $\leq 0.03-\overline{8}$ & 99.9 \\
\hline Piperacillin/tazobactam & 1299 & 1.00 & 2.00 & $\leq 0.25-8$ & 100.0 & 880 & 1.00 & 1.00 & $\leq 0.25-8$ & 100.0 \\
\hline Ceftriaxone & 1299 & 2.00 & 4.00 & $0.5-\geq 128$ & 98.9 & 880 & 2.00 & 4.00 & $0.25-16$ & 99.1 \\
\hline Imipenem & 473 & $\leq 0.12$ & 0.25 & $\leq 0.12-8$ & 99.8 & 365 & $\leq 0.12$ & 0.25 & $\leq 0.12-1$ & 100.0 \\
\hline Meropenem & 756 & $\leq 0.12$ & 0.25 & $\leq 0.12-8$ & 99.7 & 515 & $\leq 0.12$ & 0.25 & $\leq 0.12-4$ & 100.0 \\
\hline Levofloxacin & 1299 & 0.12 & 0.50 & $\leq 0.06-\geq 64$ & 95.9 & 880 & 0.12 & 0.50 & $\leq 0.06-\geq 64$ & 94.5 \\
\hline Linezolid & 1299 & 2.00 & 4.00 & $\leq 0.5-4$ & 100.0 & 880 & 2.00 & 4.00 & $\leq 0.5-4$ & 100.0 \\
\hline Vancomycin & 1299 & 1.00 & 1.00 & $\leq 0.12-4$ & 99.8 & 880 & 1.00 & 1.00 & $\leq 0.12-4$ & 99.9 \\
\hline Minocycline & 1299 & $\leq 0.25$ & 0.50 & $\leq 0.25-\geq 16$ & 99.2 & 880 & $\leq 0.25$ & $\leq 0.25$ & $\leq 0.25-\geq 16$ & 99.7 \\
\hline Tigecycline & 1299 & 0.12 & 0.25 & $0.03-0.5$ & 100.0 & 880 & 0.12 & 0.25 & $0.015-0.5$ & 100.0 \\
\hline \multicolumn{11}{|l|}{ Methicillin-resistant isolates } \\
\hline Levofloxacin & 721 & 8.00 & $\geq 64.00$ & $\leq 0.06-\geq 64$ & 17.9 & 714 & 16.00 & $\geq 64.00$ & $\leq 0.06-\geq 64$ & 6.7 \\
\hline Linezolid & 721 & 2.00 & 4.00 & $\leq 0.5-4$ & 100.0 & 714 & 2.00 & 4.00 & $\leq 0.5-4$ & 100.0 \\
\hline Vancomycin & 721 & 1.00 & 1.00 & $\leq 0.12-2$ & 100.0 & 714 & 1.00 & 1.00 & $0.25-4$ & 99.9 \\
\hline Minocycline & 721 & $\leq 0.25$ & 4.00 & $\leq 0.25-\geq 16$ & 93.5 & 714 & $\leq 0.25$ & 4.00 & $\leq 0.25-\geq 16$ & 95.1 \\
\hline Tigecycline & 721 & 0.12 & 0.25 & $0.03-0.5$ & 100.0 & 714 & 0.12 & 0.25 & $\leq 0.008-0.5$ & 100.0 \\
\hline
\end{tabular}

With the exception of methicillin resistance, no major differences are evident when comparing susceptibility data of bloodstream isolates of $S$. aureus (MSSA and MRSA) from non-ICU and ICU settings (Table 3).
No major differences in susceptibility are observed when comparing isolates from patients aged 18-64 years and $\geq 65$ years of age with the exception of levofloxacin against MRSA. In the case of this fluoroquinolone, while $17.9 \%$ of those isolates from 
patients aged 18-64 years are susceptible, only $6.7 \%$ among isolates from patients aged $\geq 65$ years are susceptible (Table 4).

\section{DISCUSSION}

Bloodstream infection is a serious medical condition associated with high mortality, which can be reduced by initiation of prompt and appropriate empirical antimicrobial therapy (Bates et al., 1995; Mylotte et al., 2001; Hanon et al., 2002). S. aureus is a serious cause of bacteremia and successful treatment of this important pathogen is complicated by methicillin and multi-drug resistance, with rates of resistance higher amongst isolates cultured from patients in ICU rather than non-ICU settings and also from the elderly (Safdar and Maki, 2002; Cosgrove et al., 2003; Biedenbach et al., 2004; Cosgrove, 2006). MRSA bacteraemia has been shown to be more life threatening than MSSA due to the inferior efficacy of vancomycin which remains the standard treatment of serious MRSA infections in many countries (Turnidge et al., 2009). Against this background, continuing surveillance of the antimicrobial susceptibility of bacterial pathogens, including $S$. aureus and the development and characterization of new compounds are essential (Zinner, 2005; Zhanel et al., 2008).

Most pharmaceutical and biotechnology companies have reduced or ceased development of new antimicrobial agents in recent years, despite the continual threat to public health caused by the increasing prevalence of antibacterial resistance. One key reason is that considerably larger profits can be made through the development and sale of drugs for chronic medical conditions (Infectious Diseases Society of America, 2004; Payne et al., 2007). Tigecycline is one of a small number of new antimicrobials to have undergone successful clinical development recently and was licensed by the Food and Drug Administration (FDA) of the USA in 2005 and by the European Medicines Agency (EMEA) in 2006 for use in the treatment of complicated skin and skin structure infections and complicated intra-abdominal infections caused by a variety of susceptible bacterial pathogens including MSSA and MRSA (European Medicines Agency, 2009; Wyeth Pharmaceuticals Inc, 2009a; $2009 b)$. Tigecycline is unaffected by the majority of clinically important resistance mechanisms, including those two key in the expression of tetracycline resistance-ribosomal protection and efflux pumps-and methicillin resistance in staphylococci. TEST was established in 2004 as a global surveillance programme designed to monitor the in vitro activity of tigecycline and to compare it with that of other antimicrobials in common clinical use against a wide range of bacterial species, including antimicrobial-resistant strains (Wyeth Pharmaceuticals Inc, 2009a; 2009b).

In this study, we have reported on the susceptibility of bloodstream isolates of $S$. aureus to tigecycline and a range of comparator compounds, collected by centers worldwide and submitted to the TEST programme during the period 2004-2008. All of the isolates of Staphylococcus aureus included in the study, whether MSSA or MRSA strains, were inhibited by tigecycline at a concentration of $0.5 \mathrm{mg} \mathrm{L}^{-1}$ or less, indicating clinical susceptibility regardless of the activity of comparators.

Antimicrobial resistance is more likely to be encountered among bacterial isolates cultured from patients treated on ICUs and those considered elderly (Safdar and Maki, 2002; Biedenbach et al., 2004). There is some evidence for this in the case of methicillin resistance among the combined isolates (non-ICU Vs ICU isolates, MRSA occurrence $=38.2 \%$ Vs $45.5 \%$; age 18-64 Vs $\geq 65$ years, MRSA occurrence $=37.0 \%$ Vs $44.8 \%$ ). However, since no representatives of the aminglycosides, the macrolides or inhibitors of folate synthesis were tested, coupled with the fact that all isolates were susceptible to linezolid and at least $99.8 \%$ to vancomycin, the association between resistance and whether isolates were sourced from ICU and the elderly patients could not be tested robustly in this study.

Staphylococcus aureus susceptibility to the fluoroquinolone levofloxacin increased significantly during the course of this study, with increasing MSSA susceptibility and decreasing MRSA susceptibility reported between 2004 and 2008. One possible explanation for this is real change in $S$. aureus susceptibility brought on by more judicious use of betalactam antibiotics in recent years. As awareness of the risks of MRSA increases, current treatment regimens may exert less selective pressure on the mecA genes which cause methicillin resistance. Continued observation of MRSA susceptibility rates via surveillance studies such as TEST will reveal if this trend continues.

The development of new antimicrobials unaffected by current, commonly occurring mechanisms of resistance is of critical importance if the advantages of infection control, made possible by antimicrobial therapy and prophylaxis during the past 50 years, are to be maintained.

\section{CONCLUSION}

Tigecycline is indicated in the treatment of cSSSIs, cIAIs and CABP caused by penicillin- 
susceptible $S$. pneumoniae or $\beta$-lactamase negative $H$. influenzae. Although tigecycline is not indicated for the treatment of bloodstream infections, the results of this analysis of bloodstream isolates of $S$. aureus submitted to the TEST programme during the period 2004-2008 clearly demonstrate the potent activity of tigecycline and indicate its potential in the treatment of this challenging pathogen.

\section{ACKNOWLEDGEMENT}

This study was sponsored by Wyeth which was acquired by Pfizer Inc in October 2009. Medical writing support for this manuscript was provided by David Felmingham and Rod Taylor of Micron Research Ltd and was funded by Wyeth.

The authors thank the investigators and center staff who submitted isolates and data to the TEST study. They also wish to thank the staff of International Health Management Associate (IHMA) for their coordination of the TEST study data and the staff of Micron Research Ltd, Chatteris, UK for codification and analysis of data.

Daniel Amsterdam is on the Speakers Bureau of Astellas Pharmaceuticals. Michael J Dowzicky is an employee of Wyeth Pharmaceuticals.

\section{REFERENCES}

Bates, D.W., K.E. Pruess and T.H. Lee, 1995. How bad are bacteraemia and sepsis? Outcomes in a cohort with suspected bacteraemia. Arch. Intern. Med., 155: 593-598, PMID: 18668183

Biedenbach, D.J., G.J. Moet and R.N. Jones, 2004. Occurrence and antimicrobial resistance pattern comparisons among bloodstream isolates from the SENTRY antimicrobial surveillance program (1999-2002). Diagn. Microbiol. Infect. Dis., 50: 59-69. PMID: 15380279

Chastre, J., 2008. Evolving problems with resistant pathogens. Clin. Microbiol. Infect., 14: 3-14. PMID: 18318874

CLSI., 2009a. M07-A8 (Vol. 29 No. 2): Methods for Dilution Antimicrobial Susceptibility Tests for Bacteria that Grow Aerobically; Approved Standard. 8th Edn., Clinical Laboratory Standards Institute, Wayne, Pennsylvania, ISBN: 1-56238689-1, pp: 65.

CLSI., 2009b. M100-S19 (Vol. 29 No. 3): Performance Standards for Antimicrobial Susceptibility Testing; Nineteenth Informational Supplement. Clinical Laboratory Standards Institute, Wayne, Pennsylvania, ISBN: 1-56238-690-5, pp: 149.
Cosgrove, S.E., 2006. The relationship between antimicrobial resistance and patient outcomes: Mortality, length of stay and health care costs. Clin. Infect. Dis., 42: 82-89, PMID: 16355321

Cosgrove, S.E., G. Sakoulas, E.N. Perensevich, M.J. Scwaber and A.W. Karchmer et al., 2003. Comparison of mortality associated with methicillin-resistant and methicillin-susceptible Staphylococcus aureus bacteraemia: A meta-analysis. Clin. Infect. Dis., 36: 53-59, PMID: 12491202

Deasy, J., 2009 Antibiotic resistance: The ongoing challenge for effective drug therapy. J. Am. Acad. Phys. Assist., 22: 18-22, PMID: 19354110

European Medicines Agency, 2009. Tygacil. http://www.emea.europa.eu/humanadocs/Humans/ EPAR/tygacil/tygacil.htm

Felmingham, D., 2002. The need for antimicrobial resistance surveillance. J. Antimicrob. Chemother., 50: 1-7. PMID: 12239224.

Felmingham, D., 2005. Tigecycline the first glycylcycline to undergo clinical development: An overview of in vitro activity compared to tetracycline. J. Chemother., 17: 5-11. PMID: 16285353

Hanon, F.X., D.L. Monnet, T.L. Sorensen, K. Molbak and G. Pedersen et al., 2002. Survival of patients with bacteraemia in relation to initial empirical antimicrobial treatment. Scand. J. Infect. Dis., 34: 520-528, PMID: 12195878

Infectious Diseases Society of America, 2004. Bad bugs, no drugs. http://www.idsociety.org/badbugsnodrugs.html

Isturiz, R., 2008. Global resistance trends and the potential impact on empirical therapy. Int. J. Antimicrob. Agents, 32: 201-206. PMID: 19134520

Klein, E., D.L. Smith and R. Laxminarayan, 2007. Hospitalizations and deaths caused by methicillinresistant Staphylococcus aureus. United States, 1999-2005. Emerg. Infect. Dis., 13: 1840-1846. PMID: 18258033

Lodise, T.P. and P.S. McKinnon, 2005. Clinical and economic impact of methicillin resistance in patients with Staphylococcus aureus bacteraemia. Diagn. Microbiol. Infect. Dis., 52: 113-122. PMID: 15964499

McDonald, L.C., 2006. Trends in antimicrobial resistance in healthcare-associated pathogens and effect on treatment. Clin. Infect. Dis., 42: S65-71. PMID: 16355319

Murray, P.R., 2007. Manual of Clinical Microbiology. 9th Edn., ASM Press, Herndon VA., pp: 2488. 
Mylotte, J.M., L. Kahler and C. McCann, 2001. Community-acquired bacteraemia at a teaching Vs non-teaching hospital: Impact of acute severity of illness on 30-day mortality. Am. J. Infect. Cont., 29: 13-19. PMID: 11172313

Office for National Statistics, 2009. Statistical bulletin. deaths involving MRSA: England and Wales. http://www.statistics.gov.uk/pdfdir/mrsa0809.pdf

Payne, D.J., M.N. Gwynn, D.J. Holmes and D.L. Pompliano, 2007. Drugs for bad bugs: Confronting the challenges of antibacterial discovery. Nat. Rev. Drug. Disc. 6: 29-40. PMID: 17159923

Rehm, S, M., D.E. Campion, R.R. Katz and H.W. Boucher, 2009. Community-based outpatient Antimicrobial Therapy (CoPAT) for Staphylococcus aureus bacteraemia with or without infective endocarditis: Analysis of the randomized trial comparing daptomycin with standard therapy. J. Antimicrob. Chemother., 63: 1034-1042, PMID: 19264792

Safdar, N. and D.G. Maki, 2002. The commonality of risk factors for nosocomial colonization and infection with antimicrobial-resistant Staphylococcus aureus. Enterococcus, Gram negative bacilli, Clostridium difficile and Candida. Ann. Intern. Med., 136: 834-844. PMID: 12044132

Shannon, S., J. Louie, A. Siniscalchi and E. Rico et al., 2009. Surveillance for pediatric deaths associated with 2009 Pandemic Influenza A (H1N1) Virus Infection-United States, April-August 2009. Morb. Mortal. Wkly. Rep., 58: 941-947. PMID: 19730406
Turnidge, J.D., D. Kotsanas, W. Munckhof, S. Roberts and C.M. Bennett et al., 2009. On behalf of the Australia New Zealand cooperative on outcomes in staphylococcal sepsis. Staphylococcus aureus Bacteraemia: A Major Cause of Mortality in Australia and New Zealand. Med. J. Aust., 191: 368-373, PMID: 19807625

Wyeth Pharmaceuticals Inc., 2009a. Tygecycline Evaluation and Surveillance Trial (TEST). http://www.testsurveillance.com

Wyeth Pharmaceuticals Inc., 2009b. Tygacil product insert. http://www.wyeth.com/hcp/tygacil

Zhanel, G.G., J.A. Karlowsky, E. Rubinstein and D.J. Hoban, 2006. Tigecycline: A novel glycylcycline antibiotic. Exp. Rev. Anti-Infect. Ther., 4: 9-257. PMID: 16441206

Zhanel, G.G., M. DeCorby, K.A. Nichol, A. Wierzbowski and P.J. Baudry et al., 2008. The canadian antimicrobial resistance alliance. Antimicrobial susceptibility of 3931 organisms isolated from intensive care units in Canada: Canadian National Intensive Care Unit Study, 2005/2006. Diagn. Microbiol. Infect. Dis., 62: 67-80. PMID: 18513913

Zinner, S.H., 2005. The search for new antimicrobials: Why we need new options. Exp. Rev. Anti-Infect. Ther., 3: 907-913. PMID: 16307503 